\title{
ABUSO SEXUAL NA INFÂNCIA: A VIVÊNCIA EM UM AMBULATÓRIO DE PSICOTERAPIA DE CRIANÇAS
}

\section{SEXUAL ABUSE IN CHILDREN AND PLAY-THERAPY: REPORT OF AN OUT-PATIENT CLINIC}

\author{
Maria Cristina Brisighello Boarati ${ }^{1}$ \\ Maíra Bonafé Sei ${ }^{2}$ \\ Sérgio Luiz Saboya Arruda ${ }^{3}$
}

Boarati MCB et al. Abuso sexual na infância: a vivência em um ambulatório de psicoterapia de crianças. Rev Bras Crescimento Desenvolv Hum. 2009; 19(3): 412-425.

\section{Resumo:}

O Ambulatório de Psicoterapia de Crianças é um serviço do Setor de Saúde Mental da Criança e do Adolescente. Funciona no Hospital das Clínicas da UNICAMP, recebe encaminhamentos de ambulatórios do próprio hospital e de outros serviços do município e região e oferece as seguintes modalidades de atendimento segundo o referencial psicodinâmico: psicoterapia lúdica individual, grupal e orientação de pais. Considera-se que a criança é um ser em desenvolvimento e que intervenções no âmbito psíquico podem ter tanto uma dimensão terapêutica, como um caráter preventivo. Objetivou-se apresentar o funcionamento deste ambulatório a partir do relato de uma experiência de psicoterapia de uma criança que havia sofrido abuso sexual. Buscou-se tecer considerações teóricas acerca do desenvolvimento emocional da criança e do abuso sexual na infância e discutir as possíveis intervenções neste contexto. Percebeu-se a importância do acolhimento da família como um todo, afetada pela ocorrência do abuso sexual, além do diálogo entre serviços, algo facilitado no atendimento institucional.

Palavras-chave: psicoterapia lúdica; criança; hospital; abuso sexual infantil.

Maria Cristina Brisighello Boarati. Psicóloga. Especialista. Departamento de Psicologia Médica e Psiquiatria - FCM-UNICAMP.

2 Maíra Bonafé Sei. Psicóloga. Mestre. Doutoranda em Psicologia Clínica pelo Instituto de Psicologia da Universidade de São Paulo. Departamento de Psicologia Médica e Psiquiatria - FCM-UNICAMP.

3 Sérgio Luiz Saboya Arruda. Departamento de Psicologia Médica e Psiquiatria - FCM-UNICAMP.

Correspondencia para: Maíra Bonafé Sei

Rua Dirce Barbieri Gianese, 168 - Vila São João - Campinas - SP - CEP: 13084-568 - E-mail: mairabonafe@hotmail.com Departamento de Psiquiatria e Psicologia Médica da Faculdade de Ciências Médicas da Universidade Estadual de Campinas UNICAMP 


\begin{abstract}
:
The ambulatory clinic of Psychotherapy for children is a service in the mental health of infants and adolescents sector. This service functions in a clinic at Hospital UNICAMP. It receives ambulatory referrals from both the hospital and other services in the city and from regional areas. It offers the following modes of attendance according to the referral made by the psychologist these include: Individual playful psychotherapy, group work and orientation of the parents. It is considered that the infant is a human in developing and that interventions in the psychological scope can do so much in the therapeutic dimension and also as a preventive measure. The objective of the article is to introduce the operations of the ambulatory clinic based on the account of an experience by an infant in psychotherapy that suffered sexual abuse. Its aim is to build on theoretical considerations about the emotional development of the infant and of the sexual abuse that occurs in infancy and discusses the possible interventions in this context. It perceives the importance of creating a warm, caring and sympathetic environment for the family unit, that has been affected by the occurrence of sexual abuse, beyond the dialogue between services, this is something facilitated in the institutional service.
\end{abstract}

Key words: psychotherapy; child; hospital; child sexual abuse.

\section{INTRODUÇÃO}

A violência sexual é considerada, pela Organização Mundial de Saúde ${ }^{1}$, um problema global tanto no senso geográfico, por estar presente em todos os países do mundo e níveis da sociedade, como por atingir pessoas de ambos os sexos e de todas as idades. Quanto à conceituação, a OMS aponta que a terminologia utilizada pode variar de acordo com a abordagem médica, social, país e regiões de um mesmo país. É definida como qualquer ato sexual ou tentativa de obter um ato sexual, por meio do uso de força ou de coerção, ameaças de danos por qualquer pessoa, independente do grau de relação com a vítima e do ambiente no qual a violência ocorre. ${ }^{1}$

Dados da Secretaria de Estado da Saúde do Estado de São Paulo ${ }^{2}$ apontam que 43\% dos casos de violência sexual,atendidos no Hospital Pérola Byington do município de São Paulo, no ano de 2007, referem-se a crianças de até 11 anos de idade. Além disso, indivíduos próximos à criança, como pais, padrastos, amigos da família e vizinhos, são os maiores responsáveis pela agressão. ${ }^{2}$
Adicionalmente, dados de pesquisa em processos jurídicos de casos de violência sexual contra crianças e adolescentes apontaram que as meninas são as maiores vítimas, com a violência tendo ocorrido entre os 5 e 10 anos de idade, mas com a revelação feita apenas na adolescência. ${ }^{3}$ Observou-se a necessidade de capacitação profissional para identificação e diagnóstico da violência sexual, com promoção de intervenções que objetivem a prevenção e terapia. Neste sentido, nota-se uma "carência de ações efetivas na condução e na prevenção do problema"4 (p. 210), com poucos serviços que ofertem o amparo necessário às vítimas.

As conseqüências no âmbito da saúde são variadas e numerosas, incluindo efeitos no campo físico e emocional, a curto e longo prazo $^{1}$, além de haver um consenso na literatura acerca do ciclo de repetição do fenômeno que se estabelece nas pessoas que sofreram maustratos., ${ }^{5,6}$ A partir de um viés psicanalítico, considera-se que o fato traumático pode ser reproduzido, mesmo que sutilmente, nos relacionamentos que se estabelecem, com características de "isolamento e indisponibilidade para relacionamentos, 
sobretudo amorosos, e entre as gerações, em uma cadeia de violências intrasubjetivas, intersubjetivas e transubjetivas" (p. 30-1). Pela complexidade do fenômeno, as intervenções neste campo devem se pautar na interdisciplinaridade, com necessidade de boa comunicação entre os profissionais e serviços que atuam com esta população. ${ }^{8}$

A partir de um referencial psicanalítico, considera-se que a criança necessita de um ambiente suficientemente bom para um desenvolvimento emocional saudável, que não falhe além da capacidade da criança de suportar a falha. ${ }^{9}$ Transtornos diversos podem surgir quando o meio não sustenta o processo de continuidade de ser da criança. $\mathrm{O}$ abuso sexual, independentemente de ocorrer no âmbito da família ou externo à mesma, configura-se como uma situação de intrusão, que influencia negativamente no processo de desenvolvimento da criança. Ou seja, "dessa intrusão (impingement) apareceria numa distorção do desenvolvimento, em função da sensação do indivíduo, devido à experiência traumática, de ter a linha contínua de sua existência rompida pela sua própria reação automática à falha ambiental" ${ }^{5}$ (p. 36).

As falhas ambientais, como a que ocorre na violência sexual em crianças, podem gerar uma intensa angústia de aniquilamento, além de poderem acarretar dificuldades posteriores associadas à tendência anti-social. Winnicott ${ }^{10}$ aponta que esta surge quando o ambiente falha em atender as necessidades da criança na etapa de dependência relativa. Considera a tendência anti-social como um sinal de esperança de que o meio possa voltar a oferecer os cuidados um dia recebidos, mas pontua que quando esta tendência não é compreendida, pode caminhar rumo à delinqüência. ${ }^{10}$

Quanto aos dinamismos presentes no abuso sexual, ressalta-se a situação de desamparo experienciada pelo indivíduo, devido ao caráter destrutivo da situação de abuso, que se configura como "um ato de tentativa de anulação do sujeito por atacar a sua vulnerabilidade"11 (p. 219).

Não obstante, a forma como cada criança vivencia o abuso é diversa. Há aquelas que se fascinam com o abuso e se tornam, elas próprias, abusadoras; outras temem o abusador mais do que o abuso em si; outras sentem uma profunda afeição pelo abusador, outras ultrapassam os receios e sofrimentos advindos da situação de abuso; por fim, há crianças que experimentam todas estas dificuldades (Alvarez, 1994). ${ }^{12}$ Diante deste panorama, "tanto a vítima, quanto a família necessitam de acompanhamento psicológico”" (p. 347), com recomendações de que uma abordagem familiar seja adotada nas intervenções terapêuticas no âmbito do abuso sexual.

Neste artigo, objetiva-se descrever o funcionamento de um serviço ambulatorial universitário que atende crianças que sofreram abuso sexual, a partir do relato de uma psicoterapia lúdica de orientação psicodinâmica. Acredita-se que simples descrições das atividades desenvolvidas no serviço não sejam suficientes para abarcar a experiência desenvolvida em um espaço como este. Desta forma, opta-se por apresentar a prática desenvolvida no Ambulatório de Psicoterapia de Crianças do Hospital das Clínicas da Universidade Estadual de Campinas (HC-UNICAMP) e os aportes teóricos que norteiam sua clínica, por meio da discussão de um caso de abuso sexual de uma criança atendida em psicoterapia no citado ambulatório.

\section{MÉTODO}

Trata-se um estudo descritivo e qualitativo acerca do funcionamento de um serviço de psicoterapia, a partir da discussão de um caso clínico. Neste sentido, de acordo 
com Turato ${ }^{13}$, os métodos qualitativos apontam para um interesse do pesquisador em buscar o "significado das coisas, porque este tem um papel organizador nos seres humanos" (p. 510). O desenho de projeto pauta-se em recursos em aberto e flexíveis, procedimentos ajustáveis, com poucos sujeitos que representem as características de certa subpopulação. ${ }^{13}$

Quanto à pesquisa qualitativa em psicoterapia e psicanálise, Zaslavsky ${ }^{14}$ defende que "a psicoterapia e a psicanálise (aqui incluída como uma psicoterapia) devem achar e/ou definir sua própria metodologia de pesquisa, e não tentar simplesmente adaptarse a métodos extraídos de outras ciências" (p. 238). Além disso, Calil e Arruda ${ }^{15}$ argumentam que o estudo de um caso único ou de um pequeno número de casos clínicos é justificável, pois ao melhor especificar "as qualidades inerentes ao fenômeno humano, ganha também em amplitude utilizando-se não de esquemas rígidos de medição, mas da criticidade e da originalidade” (p. 198).

Com relação ao sujeito relatado, selecionou-se uma criança com história de abuso sexual que estivesse em psicoterapia lúdica segundo o referencial psicodinâmico, atendimento efetuado por um dos autores deste artigo. Trata-se de uma "amostragem proposital, deliberada ou intencional” em que o estudo do atendimento do sujeito selecionado permite a realização dos objetivos propostos, segundo os pressupostos da pesquisa clínicoqualitativa na área da saúde. “A amostragem proposital está para a pesquisa qualitativa assim como a amostragem randômica está para a pesquisa quantitativa." ${ }^{13}$ (p. 356)

Passa-se, então a apresentar o Ambulatório de Psicoterapia de Crianças e seus procedimentos de atendimento. Este é um serviço do Setor de Saúde Mental da Criança e do Adolescente, que funciona, desde 1983, no HC-UNICAMP, hospital de referência responsável pelo atendimento de casos de alta complexidade. Sua rotina de trabalho inclui a realização de avaliação psicológica, psicoterapia individual ou grupal da criança e orientação de pais, com freqüência semanal. Baseia-se, desde o princípio de suas atividades, no referencial psicodinâmico, além de se diferenciar por não estabelecer, a priori, um prazo determinado para o término do processo psicoterapêutico. Cada criança tem uma caixa lúdica individual que representa simbolicamente o mundo interno da criança. Permite que suas fantasias, angústias e medos sejam expressos principalmente pelos jogos, brinquedos e desenhos, conforme o proposto na psicanálise de crianças ${ }^{16-18}$, cuja técnica foi adaptada ao contexto de um ambulatório de uma instituição pública. ${ }^{19-22}$ Os encaminhamentos para a psicoterapia são realizados por serviços que compõem a rede pública de saúde e pelos demais ambulatórios do HC-UNICAMP. Há, assim, uma interrelação entre as atividades desenvolvidas no hospital, aspecto que garante uma atenção mais completa aos pacientes.

\section{DISCUSSÃO}

A psicoterapia nos casos de abuso sexual deve considerar a situação de desamparo e de angústia à qual a criança está submetida. Precisa atentar-se para a questão da submissão e, com isso, respeitar o ritmo do indivíduo. Como defende Alvarez ${ }^{12}$, "o processo de aprendizagem da aceitação da dor, da perda, do trauma ou do abuso é complexo, longo, nem sempre visível e com certeza não necessariamente verbalizado" (p. 161) e a situação traumática deve ser esquecida para ser lembrada.

O olhar dirigido à vítima deve transpor a violência sexual vivida e a cicatriz impingida por esta. É necessário, diferentemente, 
viabilizar a construção de identidades diversas da de vítima sexual. ${ }^{11}$

Ao se compreender que estas crianças tiveram a relação de confiança no outro abalada pelo abuso, que pode ter gerado sentimentos de insegurança, solidão e desamparo, acredita-se que o terapeuta ao "se colocar como 'continente', poderá facilitar o surgimento da 'verdade' da criança, restituindo-lhe o estatuto de sujeito" ${ }^{5}$ (p. 35).

Ao se deter exclusivamente na sexualidade, não se atende às necessidades básicas da criança, relacionadas com sentimentos de proteção, amparo e compreensão. A confiança no meio pode ser retomada pela relação com o terapeuta, que tem a função de ser um ego auxiliar que facilita à pessoa reviver situações traumáticas de acordo com suas possibilidades, por meio da sustentação emocional ao paciente e do manejo da relação terapêutica.

Para Sucar ${ }^{23}$, tem-se uma busca, na análise, de resgatar o "sentir e poder pensar a dor, permitindo a aproximação através do uso da ilusão mitigando a violência, da sua utilização de modo transformador para que o processo de humanização possa ser retomado e ampliado” (p. 74). A relação terapêutica colabora para o enfrentamento e elaboração da situação por parte da criança, com a percepção da falha advinda do abuso sexual como ambiental, aspecto fundamental quando se pensa na culpa experimentada pela criança diante da violência sofrida. $\mathrm{O}$ reconhecimento da falha como decorrente do outro é essencial para a conservação de um sentido de existência e reconstituição da imagem corporal muitas vezes dilacerada nos casos de violência sexual. ${ }^{5,24}$

A partir destas considerações teóricas, passa-se a apresentar recortes de um caso clínico, referente à Renata, que contava com 10 anos de idade quando do início da psicoterapia lúdica psicodinâmica, atendida semanalmente. Segundo relato materno, Renata sofreu, aos 4 anos de idade, abuso sexual perpetrado por um vizinho, quando ela e sua irmã brincavam. Após este fato, foi notada uma alteração no comportamento da menina que se tornou hostil, desafiadora, agressiva em casa e na escola.

Quando Renata iniciou o atendimento na Unicamp, procurou-se também ampliar o cuidado e suporte para a família. A mãe foi encaminhada para a orientação de pais e a irmã para a psicoterapia de crianças, por se perceber que toda a família foi afetada pela situação de abuso. Este desperta sentimentos diversos em cada familiar e provoca reações nas relações estabelecidas entre os mesmos e nas relações estabelecidas fora da família. Isto justifica estes encaminhamentos, possíveis tendo em vista a estrutura proporcionada pelo Ambulatório de Psicoterapia de Crianças.

Observava-se a necessidade constante da mãe em falar sobre Renata, ao listar uma série de comportamentos como: agressividade, medo, ciúmes da irmã, problemas de comportamento na escola. Havia episódios de violência física na família, quando o padrasto de Renata agredia a esposa, que faziam com que a menina se assustasse. A mãe parecia considerar a violência como algo natural e desejava que sua filha aceitasse a violência testemunhada sem questioná-la. Esta maneira de expor as questões da filha indicava uma dificuldade da mãe em ser continente, necessitando ela própria ser ouvida e contida, fato que gerou o encaminhamento da mãe para orientação de pais.

Renata contou à mãe que via os pais tendo relações sexuais, algo que era facilitado já que o quarto não tinha portas. Renata sabia mais do que a família supunha acerca de sexo. Conversava a respeito deste tema com a irmã mais nova, além de haver manipulado o pênis do irmão de 4 anos ao banhá-lo, com pedidos de que este o colocasse em seu "bumbum". Na escola, relatou o abuso sofrido aos 4 anos a uma colega, que contou aos demais, 
situação que desencadeou bullying. Neste recinto, espiava as colegas no banheiro, abaixava suas roupas e as provocava.

Desde a primeira sessão, sempre solicitou a participação da terapeuta nas atividades lúdicas. Parecia mostrar o quanto sua mente estava em pedaços que precisavam de alguém que a ajudasse a se encaixarem. À medida que a terapia progredia, suas experiências iam formando um todo compreensível, com necessidade de um ambiente facilitador, propiciado pelo setting lúdico e pela terapeuta, que a sustentasse neste processo.

A violação do corpo de Renata e os "abusos" decorrentes da falha ambiental eram concretamente trazidos. Tentava violar os limites da sessão e adentrar na sala de consulta fora de seu horário de atendimento, ocasião em que a terapeuta atendia outra paciente. Parecia não compreender sua falha e alegava que esta era da terapeuta, que, de acordo com ela, atendia outras crianças e devia-lhe um presente de aniversário.

O comportamento de Renata dentro e fora do setting diferenciava-se intensamente, já que fora das sessões era inquieta e perturbava as pessoas. Nas sessões, era tranqüila, gentil, compenetrada e aproveitava o tempo junto com a terapeuta, talvez receando que a terapia fosse acabar, tal como havia ocorrido anteriormente. Esta preocupação também aparecia de outras formas, ao questionar o que aconteceria com o que era produzido nas sessões, ou ao se angustiar por se atrasar para as sessões.

Pintava grandes “cartazes” temáticos, que considerava bonitos. Sentia orgulho dos mesmos e os expunha na sessão. Os cartazes eram efetivamente belos, cheios de cor, de vida e de relatos que a ajudavam a compreender sua história e elaborar suas ansiedades. Pensa-se que a escolha de mostrar aquilo que é bonito relaciona-se com um movimento de apresentar aspectos não abusados de sua personalidade. ${ }^{5,10}$
Inicialmente, Renata considerava que as pinturas e produções da terapeuta eram melhores e mais bonitas que suas próprias criações. Isto se alterou ao longo das sessões, ao passar a enaltecer o que fazia e depreciar o que a psicóloga produzia. Compreende-se esta mudança como uma possibilidade de valorizar mais seus aspectos internos, com um olhar mais positivo e construtivo para si própria, advindo da relação psicoterapêutica, que proporcionava um olhar diferente daquele recebido pelo ambiente externo à terapia. Ao não focalizar o abuso, outros aspectos de Renata puderam ser expressos e fortalecidos, com possibilidade de ocupar um novo papel nesta nova relação, preenchida pelo que ela tinha de bom, algo que parecia ser possível apenas no espaço da terapia.

Ao se pensar no abuso sexual infantil como um problema de saúde pública ${ }^{1,3,8}$, considera-se relevante a apresentação e reflexão das propostas de intervenções psicológicas com esta população. $\mathrm{O}$ Ambulatório de Psicoterapia de Crianças tem como característica estar interligado aos demais serviços para contemplar as questões familiares, psiquiátricas, físicas, sociais e considera-se que, no caso apresentado, tal estrutura foi indispensável.

A mãe e a irmã de Renata foram encaminhadas, respectivamente, para orientação de pais e psicoterapia individual, além da família ser assistida pelo serviço social do hospital, com a interlocução entre serviços facilitada pelo contexto institucional, aspecto importante de acordo com a literatura. ${ }^{3-4,8}$ Considera-se, contudo, que se por um lado o atendimento multidisciplinar é necessário, por outro, pode incorrer no risco de gerar um reforço da identidade de vítima da criança, dada a constante repetição da história de abuso nos diferentes espaços de atendimento.

Quanto à psicoterapia lúdica de orientação psicodinâmica, nos casos de abuso sexual, acredita-se que não direcionar o 
atendimento e as interpretações e deixar a criança trazer o tema que lhe é pertinente criou um ambiente facilitador do desenvolvimento emocional. Foi possível para Renata expressar aspectos não abusados de sua personalidade. ${ }^{11-}$ ${ }^{12}$ Ao se observar a pouca condição da mãe para acolher as angústias suscitadas após a revelação do abuso e as conseqüências deste também no ambiente externo ao familiar, considera-se que a orientação de pais, realizada com a mãe, foi relevante para a colaboração e aderência desta ao tratamento da filha. ${ }^{8,22}$

\section{REFERÊNCIAS}

1. World Health Organization (WHO) Guidelines for medico-legal care for victims of sexual violence. Geneva; 2003. [acesso em 08 jun 09] Disponível em: http://whqlibdoc.who.int/ publications/2004/924154628X.pdf

2. Secretaria de Estado da Saúde-SP. Crianças são as principais vítimas de violência sexual. 10 de Março de 2008. [acesso em 03 jan 09] Disponível em: http://portal.saude.sp.gov.br/content/ digevovegi.mmp

3. Habigzang LF, Koller SH, Azevedo GA, Machado PX. Abuso sexual infantil e dinâmica familiar: aspectos observados em processos jurídicos. Psicologia: Teoria e Pesquisa 2005; 21(3): 341-48.

4. Aded NLO, Dalcin BLGS, Morais TM, Cavalcanti MT. Abuso sexual em crianças e adolescentes: revisão de 100 anos de literatura. Revista de Psiquiatria Clínica 2006; 33(4): 204-13.

5. Junqueira MF. O abuso sexual da criança e a prática clínica: sexualidade e desamparo. Psicologia Clínica 1998/ 1999; 10(10): 25-42.
Por fim, os autores deste artigo pensam que esta estratégia de intervenção colabora não somente para o desenvolvimento emocional da criança ${ }^{19-22}$, como também para uma interrupção no ciclo de violência estabelecido nas pessoas vitimizadas, que freqüentemente perpetuam a violência sofrida ${ }^{6-7}$ Por fim, considera-se a inclusão de serviços ambu-latoriais de psicoterapia de crianças ${ }^{5,7,12,23,24}$ que propiciam assistência à família ${ }^{3-4,8}$ como algo a ser valorizado ao se traçarem políticas públicas de saúde no campo do abuso sexual contra crianças.

6. Paiva MLSC, Gomes IC. Violence familiale, transgénérationnel et pacte dénégatif. Revue de thérapie familiale psychanalytique 2007; 18: 139-52.

7. Almeida-Prado MCC, Féres-Carneiro T. Abuso sexual e traumatismo psíquico. Interações 2005; 10(20): 11-34.

8. Habigzang LF, Azevedo GA, Koller SH, Machado PX. Fatores de risco e de proteção na rede de atendimento a crianças e adolescentes vítimas de violência sexual. Psicologia: Reflexão e Crítica 2006; 19(3): 379-86.

9. Winnicott DW. A preocupação materna primária. 1956 In: Winnicott, D. W. Da pediatria à psicanálise: obras escolhidas. Rio de Janeiro: Imago; 2000. p. 399-405.

10. Winnicott DW. A delinqüência como sinal de esperança. 1967 In: Winnicott DW. Tudo começa em casa. São Paulo: Martins Fontes; 1999. p. 81-91.

11. Junqueira MFPS. Violência e abuso sexual infantil: uma proposta clínica. Cadernos de Psicanálise (SPCRJ) 2002; 18(21): 209-26. 
12. Alvarez A. Companhia viva: psicoterapia psicanalítica com crianças autistas, borderline, carentes e maltratadas. Porto Alegre: Artes Médicas; 1994.

13. Turato ER. Métodos qualitativos e quantitativos na área da saúde: definições, diferenças e seus objetos de pesquisa. Revista de Saúde Pública 2005; 39(3): 507-14.

14. Zaslavsky J. Por que publicar a pesquisa qualitativa em psicoterapia e psicanálise? Revista de Psiquiatria do Rio Grande do Sul 2005; 27(3): 238-9.

15. Calil RCC, Arruda SLS. Discussão da pesquisa qualitativa com ênfase no método clínico. In: GRUBITS S, Noriega JAV. Método qualitativo: epistemologia, complementaridades e campos de aplicação. São Paulo: Vetor; 2004. p. 173-213.

16. Klein M. A técnica psicanalítica através do brincar: sua história e significado. 1955 In: KLEIN M. Inveja e gratidão e outros trabalhos (1946-1963). Rio de Janeiro: Imago; 1991. p. 149-68.

17. Aberastury A. Psicanálise da criança: teoria e técnica. Porto Alegre: Artes Médicas; 1982.

18. Ferro A. A técnica na psicanálise infantil. A criança e o analista: da relação ao campo emocional. Rio de Janeiro: Imago; 1995.
19. Aguirre SB, Arruda SLS. Psicoterapia lúdica de uma criança com AIDS. Estudos de Psicologia 2006 23(3): 22937.

20. Arruda SLS, Carneiro GRS. Criança e terapeuta que adormecem na psicoterapia: relato de casos. Revista Brasileira de Psicoterapia 2006; 8(2-3): 226-40.

21. Hildebrand N, Arruda SLS. Sintomas do não saber: contribuições ao conceito de inibição intelectual em crianças.

Pulsional Revista de Psicanálise 2008; 21(4): 39-48.

22. Sei MB, Souza CGR, Arruda SLS. O sintoma da criança e a dinâmica familiar: orientação de pais na psicoterapia infantil. Vínculo: revista do NESME 2008; 5(2): 194-205.

23. Sucar IZ. No resgate da alma. Revista Brasileira de Psicanálise 2008; 42(2): 69-80.

24. Azevedo EC. Atendimento psicanalítico a crianças e adolescentes vítimas de abuso sexual. Psicologia: Ciência e Profissão 2001; 21(4): 66-77.

Recebido em: 28 de junho de 2008. Modificado em: 10 de março de 2009. Aceito em: 25 de agosto de 2009. 


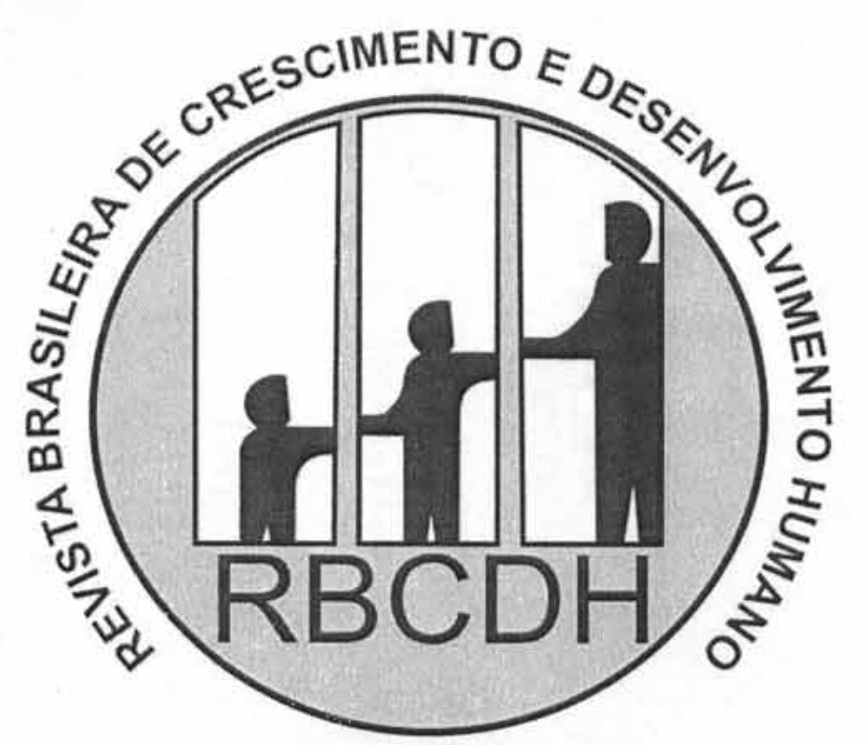

Qualis CAPES 2009: B2

\section{ANAIS}

\section{CONGRESSO INTERNACIONAL}

DE SAÚDE DA CRIANÇA E DO ADOLESCENTE PERÍODO: 26 A 29 DE AGOSTO DE 2010

LOCAL: FACULDADE DE SAÜDE PÜBLICA DA UNIVERSIDADE DE SÄO PAULO.

Realização:

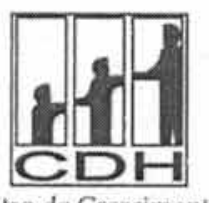

Centro de Crescimento e Desenvolvimento Humano

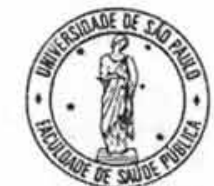

Departamento de Saúde Materno-Infantil

Apoio:

QNeNPq
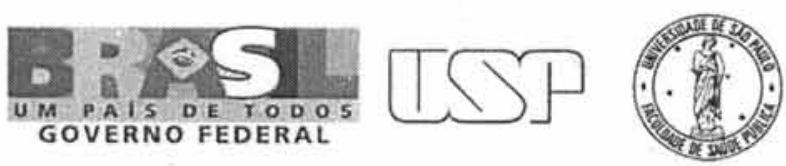